\title{
O JOGO DAS CIDADES EM TEMPOS DE MEGAEVENTOS ESPORTIVOS: ALGUMAS REFLEXÕES
}

\author{
THE GAME OF CITIES IN TIMES OF MEGA SPORTING EVENTS: SOME \\ REFLECTIONS
}

\section{EL JUEGO DE CIUDADES EN TIEMPOS DE MEGAEVENTOS DEPORTIVOS: ALGUNAS REFLEXIONES} Emília Amélia Pinto Costa da Silva*, Simone Rechia*, Priscilla Pinto Costa da
Silva**, Talita Stresser de Assis*, Clara Maria Silvestre Monteiro de Freitas $^{* * *}$

Palavras-chave

Esportes: organização \& administração

Cidades.

Participação

comunitária.

Keywords

Sports: organization \& administration.

Cities.

Community

participation.

Palabras clave

Deportes: organización \& administración.

Ciudades.

Participación

comunitaria.
Resumo: 0 ensaio objetiva analisar aspectos referentes aos megaeventos esportivos propostos para acontecer no Brasil, com o intuito de compreender seus possíveis impactos. Neste texto, são apontadas situações que o Brasil está vivendo na fase que antecede aos megaeventos, no que se refere às transformações das cidades, aos impactos no cotidiano dos moradores decorrentes de todas as mudanças exigidas, aos possíveis legados e, por fim, como a Educação Física situa-se nesse processo. Sediar megaeventos esportivos remete a estratégias complexas, sendo de fundamental importância a participação da comunidade, uma responsável gestão pública e estudos científicos, técnicos e operacionais que identifiquem, com profundidade, tais impactos.

Abstract: This paper examines aspects related to mega sporting events proposed in Brazil in order to understand their potential impacts. It points out situations that Brazil is experiencing in times preceding those mega events, with regard to changes in cities, impacts on residents' daily lives as a result of all the changes required, their possible legacy, and finally, the place of Physical Education in the process. Hosting mega sporting events implies complex strategies and crucial aspects include community participation, responsible public management as well as scientific, technical and operational studies that identify such impacts in depth.

Resumen: El estudio objetiva analizar aspectos relacionados a los megaeventos deportivos que deben ocurrir en Brasil, con el fin de comprender sus posibles impactos. El texto señala situaciones que Brasil vive en la fase que precede a los megaeventos en lo que se refiere a las transformaciones de las ciudades, los impactos en el cotidiano de los habitantes como consecuencia de los cambios exigidos, los posibles legados y, finalmente, cómo se sitúa la educación física en este proceso. Acoger a megaeventos deportivos remite a estrategias complejas, y es de fundamental importancia la participación de la comunidad, una responsable gestión pública y estudios científicos, técnicos y operacionales que identifiquen con profundidad tales impactos.
* Universidade Federal do Paraná. Curitiba, PR, Brasil.

E-mail: milapcosta@hotmail.com

** Universidade de Pernambuco/ Universidade Federal da Paraíba. João Pessoa, PB, Brasil.

E-mail: laprisci@gmail.com

*** Universidade de Pernambuco. Recife, PE, Brasil.

E-mail: clarasilvestre@uol.com.br

Recebido em: 30-09-2013 Aprovado em: 18-10-2014 (c) (1) (8) Licence 


\section{INTRODUÇÃO}

As Olimpíadas, em pouco mais de um século de existência na modernidade, têm evoluído amplamente, sendo indiscutível seu poder de reestruturação urbana, o que ocasiona 0 desejo de cidades de sediar os jogos (MASCARENHAS, 2011). Na verdade, o desejo dos países de sediar um evento esportivo não remete apenas aos Jogos Olímpicos, mas também à Copa do Mundo de futebol, além de outros eventos de grande porte. $O$ autor elege como ponto de partida o momento após a Segunda Guerra Mundial, em que os Jogos Olímpicos atraíram interesse e apoio governamental. Assim, iniciou-se um período em que o grande evento poderia se relacionar com demandas sociais como habitação, transporte e infraestrutura em geral.

Dessa forma, há países cada vez mais dispostos a investir nos megaeventos, pois 0 seu legado pode proporcionar uma reestruturação econômica, atrair investimentos, promover uma imagem positiva da cidade. No entanto, pode-se pensar que, diante da complexidade das cidades, o período de organização dos megaeventos tende a agregar (os hotéis, rotas entre aeroporto e estádios, pontos turísticos), segregar (pessoas com menor poder aquisitivo), centralizar (o consumo) e, ainda, descentralizar (a violência, os moradores de rua e a pobreza).

Neste sentido, há fatores que podem motivar a não realização dos megaeventos esportivos, como no insucesso dos Jogos Olímpicos de Montreal, em 1976, o grande gasto de dinheiro público, o risco dos eventos não alcançarem os objetivos previstos, entre outros. Raeder (2011) aponta movimentos sociais que são contra a realização de eventos dessa natureza, pelos impactos causados às cidades-sede e pela falta de retorno dos investimentos realizados. É possível perceber tais movimentos no atual momento que o Brasil está vivenciando, nesse período que antecede os megaeventos esportivos, no qual as manifestações acontecem frequentemente, principalmente nas cidades-sede.

Como exemplo, pode-se citar o alto investimento de dinheiro público disponibilizado para a realização da Copa do Mundo no Brasil, que, de acordo com os documentos do Ministério do Esporte (MINISTÉRIO DO ESPORTE, 2013), justificava-se porque o evento traria melhorias para população não apenas no que diz respeito aos estádios, que ficariam mais modernos, confortáveis e seguros, mas também seriam feitas melhorias nos aeroportos, na rede hoteleira e no transporte público, fatos que hoje, em 2014, acabaram não se concretizando na íntegra.

Desse modo, as cidades que já sediaram ou irão sediar megaeventos esportivos, como é o caso das Olimpíadas, podem receber melhorias estruturais voltadas ao esporte de rendimento, pela reestruturação urbana que está sendo feita, como, por exemplo, as construções de centros esportivos para treinamentos. Já no caso da Copa do Mundo de futebol, essas meIhorias relacionadas ao esporte são centradas nos estádios. No entanto, muitas vezes, essas mudanças aumentam as precariedades referentes à saúde, à educação, à moradia adequada, ao trabalho, à cultura, ao lazer, entre outros direitos que não são tratados como prioridade nos projetos voltados aos megaeventos esportivos.

Essas prerrogativas, principalmente no tocante ao esporte, são abordadas nos projetos e, consequentemente, nos discursos de dirigentes esportivos e gestores públicos. Muitas vezes, isso ocorre com forte apelo simbólico para atrair a simpatia e o apoio do povo brasileiro. Sabe-se, por exemplo, que, quando se fala em futebol, há uma relação de afeto culturalmente constituída e consolidada no Brasil. Mas os direitos da população, de fato, não estão garantidos e consolidados ainda para a adequada execução dos projetos. 
Essas ideias são sustentadas a partir das pesquisas do Grupo de Estudos e Pesquisa em Lazer, Espaço e Cidade (GEPLEC) ${ }^{1}$, as quais apontam que há nas cidades brasileiras falta de segurança, de acesso, de planejamento, entre outras precariedades nos espaços públicos de esporte e lazer, que criam barreiras para que tais direitos sejam garantidos.

A esse respeito, tem-se no Brasil o exemplo do Pan Americano 2007, cujos maiores legados foram os elefantes brancos ${ }^{2}$ (VAINER, 2011). Para o autor, um dos motivos de muitas obras terem se tornado elefantes brancos foi a falta de interesse público em administrar os centros esportivos recém-construídos e a falta de incentivo de uso. O Complexo Esportivo de Deodoro, a Arena Multiuso e o Parque Aquático Maria Lenk, no Rio de Janeiro, são bons exemplos dessa dificuldade. Em relação a outros países, como a África do Sul, onde se realizou a Copa do Mundo de 2010, Vainer (2011) afirma que os resultados não foram diferentes, visto que houve grande desperdício de recursos públicos e pouco foi realizado em prol da melhoria da vida dos habitantes.

Diante do contexto, o estudo norteou o seguinte questionamento: em que medida os megaeventos esportivos ocasionam impactos nas cidades? Assim, o presente estudo tem por objetivo analisar os megaeventos esportivos no Brasil com intuito de compreender seus possíveis impactos. Para tanto, a metodologia adotada está sustentada na análise bibliográfica de estudos sobre as cidades e suas relações com os megaeventos esportivos, tendo como referência autores das áreas da Sociologia, da Geografia e da Educação Física.

\section{A CIDADE NO CONTEXTO DOS MEGAEVENTOS ESPORTIVOS}

Os Jogos Olímpicos de Barcelona, em 1992, iniciaram um novo ciclo de planejamento urbano vinculado a megaeventos. O que existiu no projeto de Barcelona foi uma mistura entre 0 urbanismo cidadão referente ao espaço público e o urbanismo globalizado, que remete ao modelo da urbanização baseada em áreas de excelência, em infraestrutura viária e em micropolos industriais e tecnológicos (HARVEY, 2012). Assim, a iniciativa de Barcelona tem sido inspiração nos projetos de megaeventos esportivos em outras cidades do mundo pela necessidade que muitas metrópoles têm de encontrar experiências positivas e um modelo a ser seguido.

Desde então, a escolha das cidades-sede mobiliza grande número de concorrentes (MASCARENHAS, 2012a). O autor relata que, para os Jogos Olímpicos de 2020, entraram na disputa as cidades de Istambul, Madrid e Tóquio. Em setembro de 2013, foi divulgado pelos meios de comunicação que Tóquio venceu essa disputa. Portanto, entende-se, pelo apelo da cobertura da mídia sobre o assunto e pelo frisson causado na população mundial, que o fato de sediar os megaeventos esportivos, além de se tornar um elemento de disputa entre os países, chega a ser um sonho.

Milton Santos (2006), afirmou que oferecer melhorias na cidade sempre foi uma promessa do poder público, pois é nesse local, em oposição à zona rural, onde há maiores possibilidades para se construir uma vida com maiores chances e oportunidades. Porém, para o autor, a cidade de hoje tem outras perspectivas, principalmente a econômica, sendo uma semente de aglutinação daqueles que sofrem o lado pior da globalização, tendo como resultado a carência crescente e a perda da esperança de ter uma vida melhor para os que têm menor poder

1 Vide blog do GEPLEC http://geplecufpr.blogspot.com.br/p/biblioteca-do-geplec.html

20 termo "elefantes brancos" é uma expressão utilizada no campo político para se referir às obras públicas que não possuem utilidade. 
aquisitivo. Aproximando a fala de Santos (2006) com a realidade atual, é possível indagar se a esperança prometida pelo poder público a todos os cidadãos brasileiros - de melhoria de vida como legado da realização dos megaeventos esportivos - de fato se concretizará. Até porque, "[...] para um país como o Brasil, sediar a Copa do Mundo e as Olimpíadas em tão curto espaço de tempo soa um tanto extravagante" (DAMO, 2012, p. 77), devido à demanda de um alto investimento em setores como mobilidade urbana, turismo, transporte aéreo, deixando outras necessidades básicas como saúde, educação, moradia e lazer em segundo plano.

Não obstante, tem-se a ideia da imensidão que são as cidades brasileiras, já com forte tendência à segregação, que pode ser intensificada a partir do momento da disputa para sediar um megaevento esportivo pelo fato de separar seus espaços territoriais entre aqueles que são considerados mais importantes para realização de tais eventos esportivos e os menos importantes. Ou seja, há atenção especial para os lugares que necessitarão de investimentos para atrair o público-alvo dos eventos, no caso os atletas e turistas, e uma assepsia de "outros lugares" que possam denegrir a imagem das cidades-sede, por exemplo, as favelas brasileiras.

Mesmo diante desse contexto, cabe ressaltar que, na lógica de sediar os megaeventos esportivos, as cidades podem atrair inúmeros investimentos e, assim, garantir um salto de inovação. Obviamente, essas inovações dependerão dos projetos e dos órgãos responsáveis para tais transformações. Mas, para que isso aconteça, é necessária uma parceria entre o governo e as organizações sociais, com a participação comunitária efetiva, buscando beneficiar um número maior de pessoas.

De acordo com uma pesquisa do lbope de 2011, citada por Mascarenhas (2013), a população percebe que o governo federal será o maior beneficiado com a realização da Copa do Mundo de 2014. Em seguida, vêm os empresários do turismo e a rede hoteleira; logo após, as prefeituras das cidades-sede, os governos estaduais, os comerciantes, os empresários da construção civil, os times de futebol, a Confederação Brasileira de Futebol e a Federação Internacional de Futebol (FIFA). Nesse mesmo olhar, Vainer (2011) alega que os ganhadores da Copa do Mundo 2014 e das Olimpíadas Rio 2016 serão as grandes empreiteiras e proprietários de terras, que terão patrimônio fundiário valorizado por meio dos grandes investimentos.

De acordo com Mascarenhas (2011, p. 27), nessa dinâmica, as cidades-sede se transformam em admirável centro das atenções pelo "[...] inquestionável poder de transformação sobre os espaços onde são realizados". Desta maneira, sediar megaeventos esportivos resulta em oportunidade para um possível novo modelo de planejamento e gestão das cidades, que pode potencializar a lógica do mercado.

Além disso, eventos desse porte também poderiam contribuir para sanar determinados problemas sociais do país, muitos deles ocasionados pela globalização, porém, podem comprometer finanças públicas e aumentar ainda mais o nível de desigualdade social (MASCARENHAS, 2011). Para que esses reflexos não sejam tão perversos, destaca-se a importância da mobilização da sociedade na busca para encontrar possíveis soluções e lutar pelos seus direitos, como aponta Lefebvre (2001) na obra $O$ direito a cidade, em que o espaço-cidade deve ser significativo, democrático, gerar liberdade, justiça, e também identidade e transformação social. 


\section{IMPACTO DOS MEGAEVENTOS ESPORTIVOS PARA OS CIDADÃOS BRASILEIROS}

Hoje, no interior das cidades, tornou-se fácil identificar territórios diferenciados: de um lado, bairros com mansões e palacetes; de outro, bairros de alta vulnerabilidade social. Há nesse território também centros de negócios, o distrito industrial e o de vida noturna (ROLNIK, 2012). Rolnik (2012) considera a cidade como um imenso quebra-cabeça composto por peças diferenciadas em que cada um conhece seu lugar e se sente estrangeiro nos demais. Partindo da concepção do quebra-cabeça e aproximando a situação descrita pela estudiosa com a realidade dos megaeventos esportivos, sabe-se que se faz necessário, diante das transformações urbanas requeridas pelos órgãos responsáveis (Comitê Olímpico Internacional [COI] e FIFA) para recebê-los, remover muitos moradores dos locais em que residem, causando alto impacto na vida cotidiana das pessoas, pois elas são obrigadas a se deslocarem para regiões geralmente mais periféricas e precárias.

Ressalta-se que a questão habitacional no Brasil já é considerada problemática e, com a realização da Copa do Mundo de 2014 e as Olimpíadas no Rio de Janeiro em 2016, o número de pessoas que serão removidas por conta dos projetos urbanos em todas as cidades envolvidas será de 150.000 a 170.000 (DOSSIÊ DA ARTICULAÇÃO NACIONAL DOS COMITÊS POPULARES DA COPA, 2011). Conforme o Comitê Popular da Copa, o governo se recusou a informar quantas pessoas serão removidas, de fato, de suas respectivas casas e/ou bairros.

A realidade que o Brasil está enfrentando se aproxima do ocorrido na Copa do Mundo da África do Sul, em 2010, quando pessoas foram removidas dos lugares em que moravam de forma involuntária. Um dos moradores removidos alegou que chorou "duas vezes, a primeira quando o país foi escolhido para sediar a Copa do Mundo e, a segunda, quando teve que deixar a casa", pois ela estava dentro da área que foi "selecionada" para sediar o jogo (MASCARENHAS, 2011, p.1).

$\mathrm{Na}$ cidade de Curitiba e na região metropolitana, por exemplo, estimava-se a remoção entre 2.000 a 2.500 famílias (DOSSIÊ DA ARTICULAÇÃO NACIONAL DOS COMITÊS POPULARES DA COPA, 2011). Dessa forma, gera-se nas famílias que residem próximo aos espaços que estão no projeto de mudança medo e insegurança, pois muitas vezes não são passadas as informações precisas e, muito menos, uma notificação prévia. Além disso, ainda de acordo com o comitê, os órgãos responsáveis pelos projetos foram questionados sobre como aconteceriam as remoções e como seriam calculadas as indenizações. No entanto, os referidos órgãos ressaltaram que os orçamentos dos projetos não preveem recursos no que diz respeito à reparação das perdas dos moradores.

Quanto a isso, é interessante perceber que a maioria das famílias removidas possui renda familiar baixa e, em muitos dos casos, mora em regiões onde não há tanto interesse no tocante à especulação imobiliária. Após as reformas e construções, as mesmas áreas possivelmente terão uma supervalorização e as famílias que ali residiam não serão beneficiadas. Sendo assim, ocorre a revitalização dos espaços de desvalia, ou seja, espaços que antes não tinham valor, depois de uma reestruturação, passam a ser valorizados, no entanto, para quem pode "pagar".

Com essa supervalorização, os moradores que ali residiam não terão o direito de usufruir das melhorias estruturais, visto que deverão ser realocados para outras áreas periféricas não estruturadas. Vale ressaltar que essas realocações são definidas pelo poder público de forma 
autocrática. Diante deste contexto, seria necessário repensar essa forma de planejamento e negociação para que os investimentos referentes aos megaeventos esportivos possibilitem acesso aos espaços revitalizados, ao transporte, à segurança, à moradia de qualidade a mais pessoas.

Assim, cabe debater a respeito da moradia bem estabelecida, defendida nos estudos de Rolnik (2012) como um direito humano, um elemento fundamental para uma vida adequada. A autora aponta que, entre os componentes que tornam uma moradia adequada, está o acesso ao desenvolvimento humano e econômico, como a educação, a saúde, as oportunidades de trabalho, a cultura, o lazer, entre outros. Assim, afastar as pessoas com menor poder aquisitivo dessas oportunidades significa aumentar a falta de acesso aos bens culturais e econômicos.

Os megaeventos, portanto, não deveriam aumentar os problemas sociais, como ressalta Tavares (2011), não podem ser entendidos como uma panaceia para os problemas econômicos e sociais. Em suma, destaca-se a importância da participação da comunidade, além do diálogo com os órgãos responsáveis pelo planejamento dos eventos, para que juntos discutam a melhor solução para ambas as partes, instituindo a perspectiva positiva diante do país que sediará megaeventos esportivos.

\section{OS LEGADOS: 0 QUE FICA NO PAÍS?}

Os megaeventos esportivos, como as Olimpíadas e Copa do Mundo, geram interesse tanto na esfera pública quanto na privada, impacto social e audiência global, características que nenhum outro tipo de evento supera (TAVARES, 2011). As prioridades nos planejamentos são compreendidas de diferentes formas, a depender das cidades onde os eventos serão realizados.

Ressaltam-se as particularidades e as dimensões de cada megaevento. Por exemplo, no que se refere à Copa do Mundo do Brasil, os aspectos geográficos conduzem ao pensamento da complexidade da organização desse evento, todavia, a Copa do Mundo conta com apenas uma modalidade esportiva. Já os Jogos Olímpicos se concentram em apenas uma cidade, mas serão 28 modalidades esportivas e mais de 10 mil atletas (CARVALHO, 2013).

Em um seminário intitulado "Gestão de Legados de megaeventos esportivos", promovido pelo Ministério do Esporte e pelo Conselho Federal de Educação Física, Rodrigues e Pinto (2008, p. 23) analisaram a fala de um dos conferencistas, o Dr. Holger Preuss, que ressalta os jogos como um catalisador de melhorias na qualidade de vida. $O$ conferencista também afirma que os jogos podem contribuir no processo de aceleração referente à regeneração das cidades nas mais diferentes áreas, como "[...] habitação, transporte, segurança, convivência, educação, sucesso econômico e outros, oportunizando legados tangíveis e intangíveis".

Considera-se, portanto, legado tangível toda a infraestrutura construída para o evento (como as arenas, as reformas de aeroportos, portos e rodoviárias) e legado intangível como 0 que está relacionado à parte social (como educação, esporte, nacionalismo e valores). Dessa forma, os megaeventos podem legitimar um rol de iniciativas, além de acelerar o desenvolvimento dos legados tangíveis e intangíveis. Vale ressaltar, por exemplo, que, para um país sediar os Jogos Olímpicos, são levados em consideração os impactos relacionados com "legados". É por isso que Rodrigues e Pinto (2008) destacam que o legado necessita ser planejado bem antes do evento. 
Damo (2012, p. 46) aponta que o legado tangível deixou de ser somente o lado bom que o evento pode proporcionar. Hoje, isso é considerado uma modalidade flutuante, que possui uma quantidade de significações. 0 autor também aponta uma crítica em relação ao legado intangível, considerando que, de fato, pode haver um aumento da autoestima nacional, voltada à exposição do país de forma ampla, às possibilidades de intercâmbio com estrangeiro, à coesão interna, entre outros fatores. Contudo, o autor salienta que, para tanto, seria necessário "mensurar a relação custo/benefício dessa parafernália de coisas".

Rodrigues e Pinto (2008) ressaltam que é necessário encontrar uma forma de gestão dos legados que não atenda especificamente o esporte de rendimento e interesses particulares de determinados grupos, sendo preciso contemplar o desenvolvimento sustentável e respeitar as necessidades da sociedade em geral. Nesse sentido, percebe-se que a espetacularização, a globalização e os negócios são os únicos eixos pensados quando se discute legados.

Villano et al. (2008), tecendo análise no tocante à realização de um megaevento esportivo por meio de um planejamento consistente e responsável, defendem, a partir de cinco categorias, que os Jogos Olímpicos podem deixar possíveis legados. Para sua melhor visualização, apresenta-se um diagrama, em que tais categorias são representadas.

Diagrama 1 - possíveis legados dos megaeventos esportivos

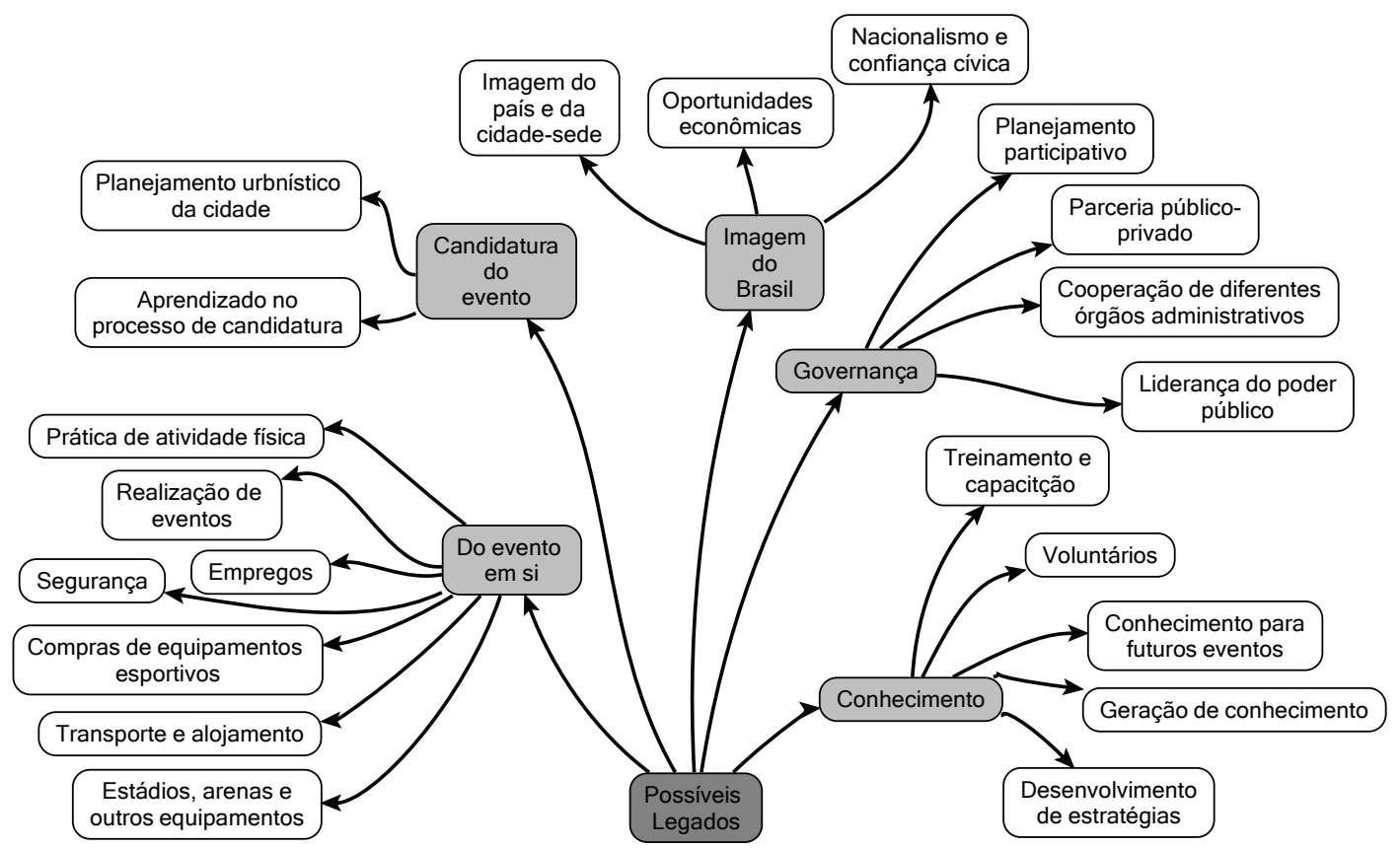

Fonte: Villano et al. (2008, p. 49-50) adaptado pelos autores

Nessa perspectiva, Villano et al. (2008) enfatizaram apenas os possíveis legados positivos. Ressalta-se que tais legados podem ser concretizados ou não, o que pode ser um fator influente, principalmente no Brasil, pela sua amplitude e particularidades regionais, como localização geográfica, cultura local, estrutura da cidade, entre outros.

Em relação aos possíveis legados negativos, que estão apresentados no diagrama 2, foram construídas quatro categorias, apresentadas a seguir. 


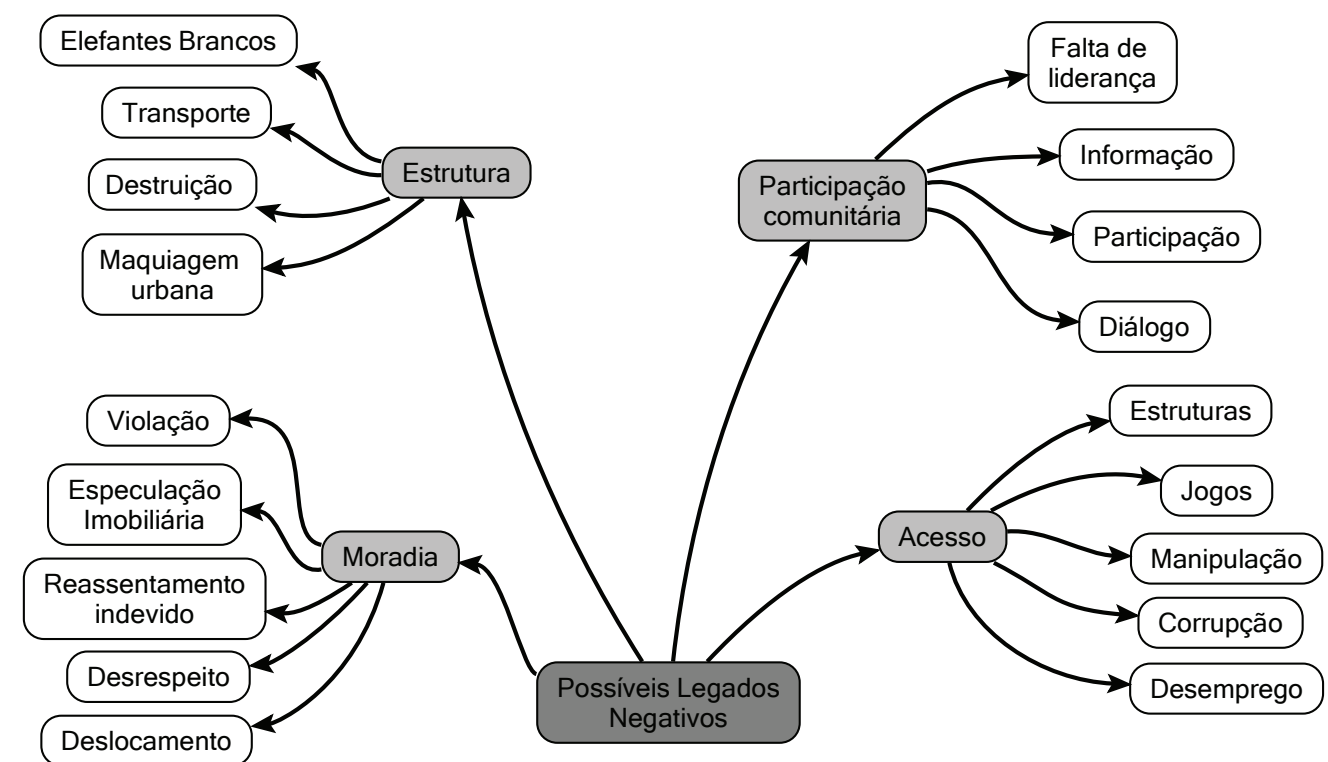

Fonte: dos autores

No tocante às especificidades de legados, o estudo de Carvalho (2013) retratou as particularidades dos possíveis legados que podem ser deixados pela Copa do Mundo de futebol e dos Jogos Olímpicos. Desta forma, para melhor compreensão, também foi construído um diagrama para ilustração que está apresentado a seguir.

Diagrama 3 - Possíveis legados positivos da Copa do Mundo e dos Jogos Olímpicos

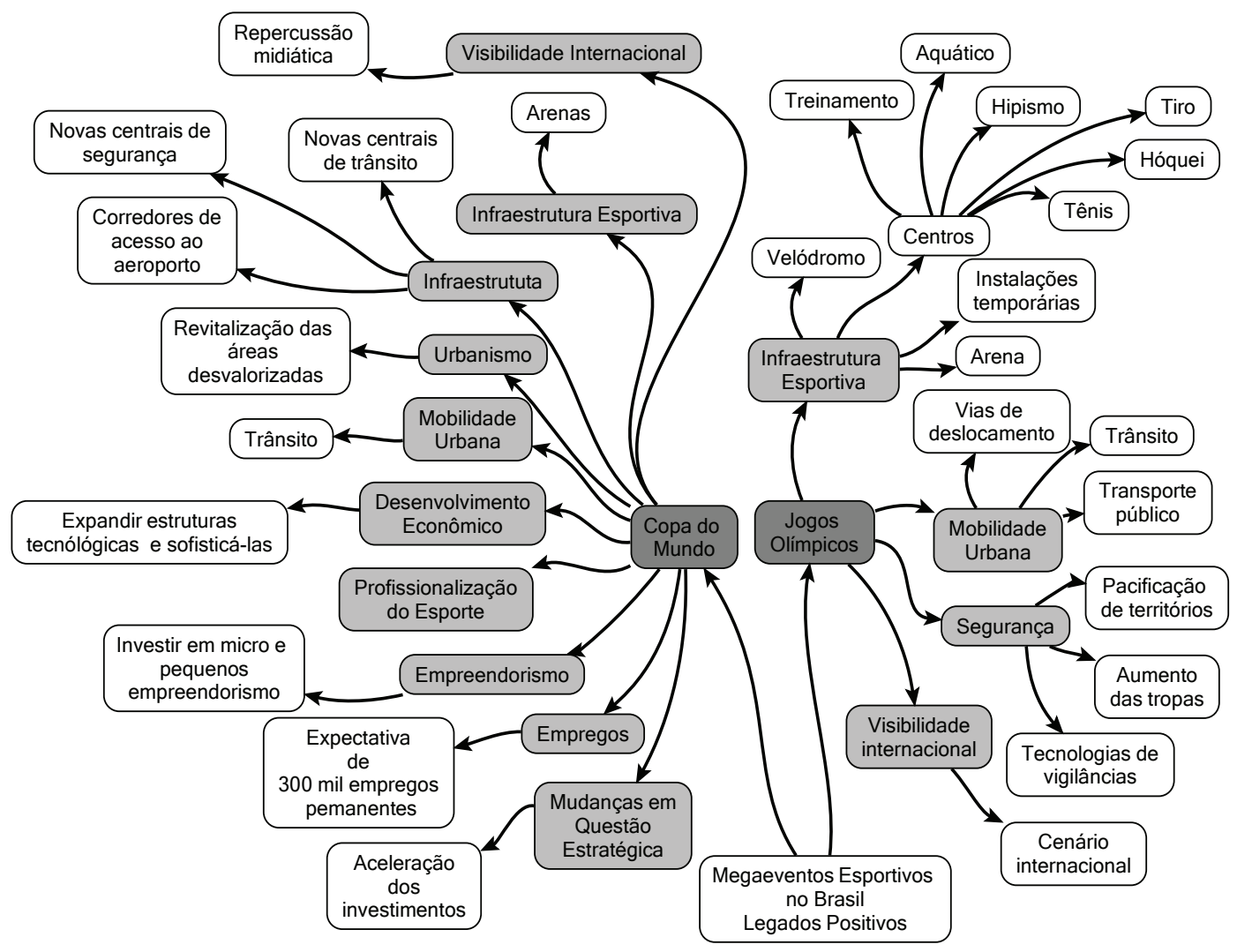


Em relação à Copa do Mundo, foram 12 cidades-sede envolvidas na realização dos jogos, mas outras cidades participaram, visto que delegações se instalaram em municípios que não se caracterizaram como cidade-sede (CARVALHO, 2013, p. 94). Contudo, o autor destaca que "centenas de municípios possam ser impactados pelos megaeventos esportivos, mas um número bem menor terá a capacidade de fazer uso desse legado".

Como pode ser observado no diagrama 3, existem possibilidades de legados que estão sendo esperados nos dois eventos. Desta forma, isso pode beneficiar o Rio de Janeiro, que sediou a Copa do Mundo e em breve sediará os Jogos Olímpicos. No tocante às demais cidades-sede da Copa do Mundo, esses legados citados são os esperados, mas agora no período pós-copa são necessários estudos em cada uma dessas cidades para analisar o que de fato ficou de legado.

Carvalho (2013) também destacou os possíveis legados negativos para os dois eventos em questão, como destaca o diagrama a seguir.

Diagrama 4 - possíveis legados negativos da Copa do Mundo e dos Jogos Olímpicos

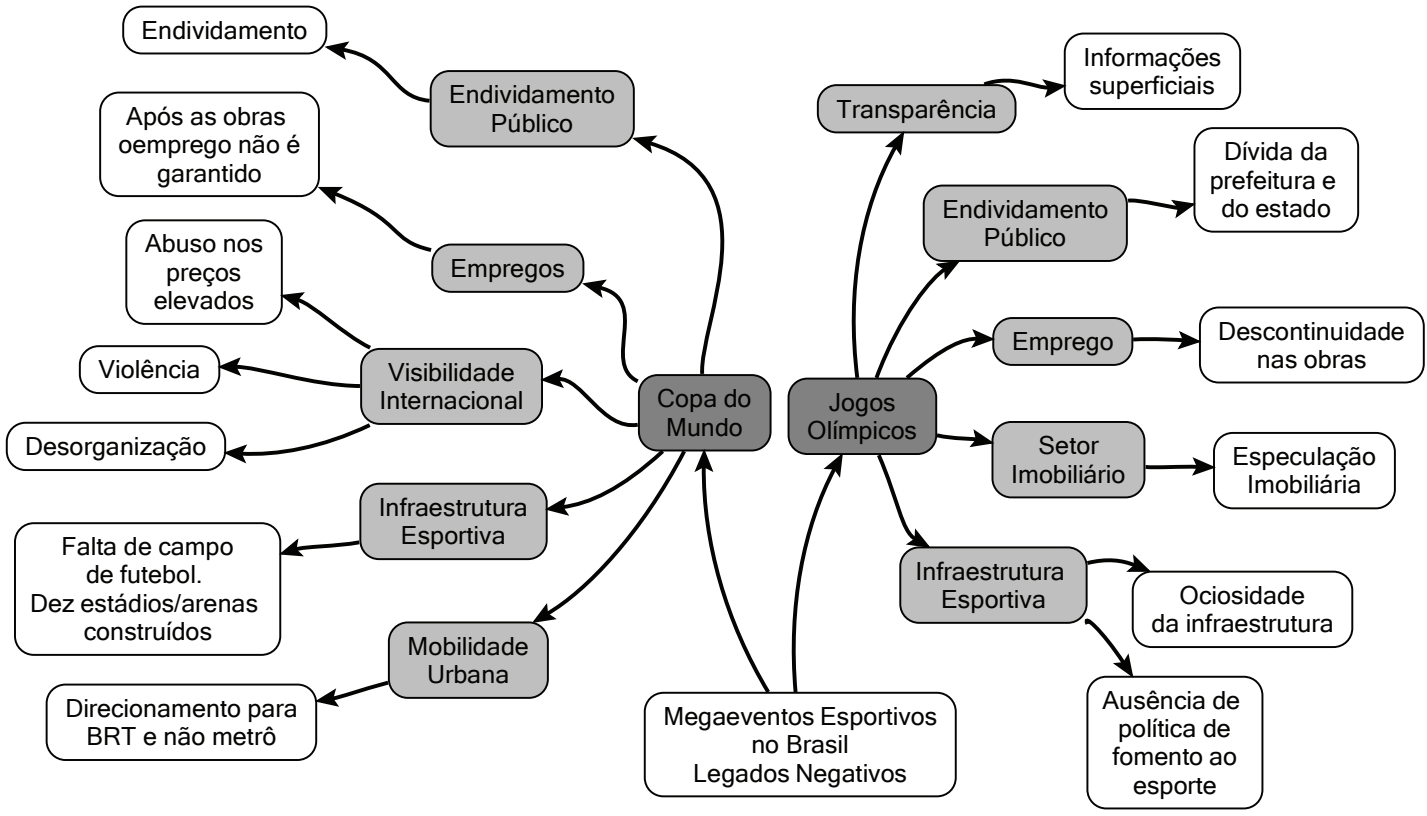

Fonte: Carvalho (2013, p. 100) adaptado pelos autores

Nesse sentido, compreende-se que sediar um evento desse porte potencializa e legitima em determinados momentos características positivas para a cidade, mas, ao mesmo tempo, pode intensificar fragilidades sociais preexistentes. Por isso, chama-se a atenção para um equilíbrio necessário na análise dos legados, sabendo que os efeitos negativos sempre existirão, mas que se espera como produto final maior número de legados positivos. Para isso, é preciso uma análise crítica quanto a outros megaeventos esportivos já realizados em outros países, tendo-os como base e como referência do que deu certo e do que não se deve fazer.

\section{COMO FICA A EDUCAÇÃO FÍSICA?}

Os Jogos Olímpicos tendem a impactar mais a área da Educação Física do que a Copa do Mundo, por envolver uma quantidade maior de modalidades esportivas. Além disso, 
há a motivação histórico-social, pois nunca alguém culpou a Educação Física pelo fracasso da Copa, ao contrário do que acontece com o quadro de medalhas de Jogos Olímpicos (MASCARENHAS, 2012b) $)^{3}$. Ou seja, quando o país perde a Copa do Mundo, a culpa geralmente é da equipe técnica, no entanto, quando o número de medalhas nas Olimpíadas não é o esperado, culpa-se a Educação Física, de forma praticamente exclusiva. Para Steinhilber (2011), o Brasil está verdadeiramente diante de um tsunami esportivo, visto a imensa "onda" que pode deixar rastros de destruição e frustração, caso a demanda pelos resultados esperados pela sociedade não seja atendida.

No caso dos Jogos Olímpicos de Londres de 2012, além da expectativa de medalhas, também havia a intenção de estimular a participação popular, tornando os indivíduos mais saudáveis por meio da prática esportiva e de atividade física (COALTER, 2004). De acordo com Coalter (2004), tem-se uma perspectiva de que, em 2020, $70 \%$ da população da capital inglesa pratiquem uma atividade moderada por 30 minutos, cinco vezes por semana. $O$ argumento de que os Jogos Olímpicos potencializam o incentivo pelas práticas corporais dos moradores da cidade-sede é cada vez mais comum nos documentos que sustentam as propostas de tais megaeventos vinculados ao esporte. No entanto, é preciso analisar com profundidade como serão efetivamente comprovadas essas mudanças de comportamento no cotidiano das cidades.

Outro ponto a ser discutido é a relação da Educação Física com o esporte, que muitas vezes são considerados sinônimos. Quando se fala em megaeventos esportivos, tem-se em mente a escola, e logo se pensa no esporte inserido nela e não no esporte como um dos conteúdos da Educação Física. Por isso que é preciso ser crítico quanto a esse ponto e entender que é possível trabalhar os megaeventos no interior da escola, mas não apenas com o pressuposto do esporte de rendimento necessário para formar atletas, pois a Educação Física estaria excluindo parte dos alunos. Os conteúdos referentes aos megaeventos esportivos, quando desenvolvidos na perspectiva pedagógica, podem ser trabalhados a partir das modalidades inseridas nas Olimpíadas de 2016, focalizando a abrangência desses jogos, incluindo estudos socioculturais onde determinadas modalidades se inserem e, claro, oportunizando experiências referentes a essas práticas.

Existe uma perspectiva positiva diante da Educação Física, partindo do pressuposto de que um possível legado de tais eventos possa ser o "aumento da procura da prática de atividades físicas" (VILLANO et al., 2008, p. 49) e, consequentemente, um incentivo às práticas corporais no contexto escolar. Não obstante, Mascarenhas (2012a) aponta uma crítica. Ele explica que, a cada ciclo olímpico, mesmo com suas diferenças, existe uma valorização do profissional de Educação Física, mas, para ele, no caso do Brasil, a ambição olímpica do governo brasileiro resulta na massificação da prática esportiva no ambiente escolar, não existindo uma preocupação em qualificar as práticas pedagógicas dessa área, no contexto escolar.

Talvez a preocupação maior do poder público seja com os negócios que podem ser trazidos para o país com ajuda do esporte e da Educação Física, tratando esses assuntos como uma mercadoria. Steinhilber (2008) alega que uma inserção globalizada do esporte pode gerar importantes impactos, o que, para o autor, remete a grandes influências nas atividades físicas. Nessa perspectiva, é importante refletir como isso irá acontecer. Será que os brasileiros vão se sentir mais motivados a aderir e a permanecer vinculados a práticas corporais a partir da realização dos megaeventos esportivos no Brasil? 
No mais, conhecer as políticas públicas relacionadas aos megaeventos esportivos e conectá-las à Educação Física é fundamental, não apenas na perspectiva da escola e/ou de rendimento, mas com uma visão mais ampliada, incluindo a saúde, a cultura, o lazer e os espaços em que essas práticas possam ser realizadas no meio urbano.

Desse modo, a busca de possíveis legados positivos, tanto tangíveis quanto intangíveis, é necessária para que não apenas a Educação Física como um todo seja beneficiada, mas também para que, por meio dos megaeventos, os cidadãos brasileiros tenham acesso a uma vida de qualidade. Para tanto, faz-se necessário valorizar o professor e a escola, ou seja, a educação como um todo, para que possamos ter, de fato, uma condição digna de existência que nos dê base para resistir a crises políticas e econômicas.

\section{CONSIDERAÇÕES FINAIS}

Pensar na organização e na realização de um megaevento remete a impactos, sejam eles positivos ou não. Nesta perspectiva, sabe-se que tanto a Copa do Mundo 2014 quanto as Olimpíadas 2016 podem beneficiar a economia, contribuindo com possíveis soluções para problemas de ordem social e estrutural das cidades, por meio das intervenções urbanas. No entanto, nem sempre a oportunidade é aproveitada de forma coerente pelos gestores, como o que pode ser observado no período que antecede a Copa do Mundo 2014 no Brasil, sendo destacados os atrasos e as irregularidades nas obras. Vale ressaltar, como exemplo desse aspecto, que foi nítida a falta de acesso à informação prévia aos cidadãos residentes nas cidades-sede do que foi ou seria modificado em função das exigências propostas pala Fifa para que tais eventos fossem realizados.

Outro fato é que muitas vezes, por questões políticas e até mesmo midiáticas, os erros são omitidos e os acertos, por sua vez, muito destacados. No Brasil, ao que tudo indica, isso não vai ser diferente de outras cidades do mundo que já sediaram um megaevento ou que já passaram por experiências similares. Além disso, é nítida a falta de acesso à informação prévia aos cidadãos residentes nas cidades-sede do que foi ou será modificado.

Contudo, a disputa para sediar tais eventos, de alguma maneira, pode ser aproveitada pelos gestores para realizar melhorias na cidade, além de promovê-la no âmbito nacional e internacional, gerando a promoção do país com o sucesso do evento e criando marcas identitárias positivas para as cidades-sedes.

Ainda que isso traga benefícios, os cuidados com os conflitos urbanos são essenciais, principalmente se as desigualdades e precariedades forem nítidas bem antes da realização dos megaeventos esportivos. Chegar a esse ponto remete à legitimação das fragilidades que ali já existiam. Não é justo realizar eventos desse porte, que requerem tantos recursos e espetacularização, maquiando a pobreza, a violência, entre outros problemas sociais.

De fato, é importante a participação da comunidade como um todo, seja a comunidade científica, a população em si, os grupos ativistas, entre outros. $O$ presente estudo apresenta limitações no que se refere às particularidades regionais das cidades-sede brasileiras que recebem/receberam um megaevento esportivo. Assim, apresenta-se esta limitação como sugestão de estudos futuros. No tocante à comunidade científica, é preciso mais estudos, principalmente pesquisas originais, com o intuito de divulgar o que está sendo realizado, quais as pretensões dos organizadores, a opinião da comunidade, com objetivo de acompanhar o processo e desenvolvimento dos projetos para o recebimento dos megaeventos. 


\section{REFERÊNCIAS}

CARVALHO, Roberto Brito de. Megaeventos esportivos: legados para a economia. In: MARCELLINO, Nelson Carvalho. Legados de megaeventos esportivos. Campinas: Papirus, 2013. p. 83- 106.

COALTER, Fred. Stuck in the Blocks? A sustainable sporting legacy? In: VIGOR, Anthony; MEAN, Melissa; TIMS, Charlie. After the Goldrush: a sustainable Olympics for London. London: Institute for Public Policy Research , 2004. p. 91- 108.

DAMO, Arlei Sander. O desejo, o direito e o dever: a trama que trouxe a Copa ao Brasil. Movimento, Porto Alegre, v. 18, n. 2, p. 41-81, abr/jun. 2012.

DOSSIÊ DA ARTICULAÇÃO NACIONAL DOS COMITÊS POPULARES DA COPA. Megaeventos e violações de Direitos Humanos no Brasil. [s.n.t], 2011. Disponível em: < http://comitepopulario. files.wordpress.com/2011/12/dossie violacoes copa completo.pdf >. Acesso em: 27 dez. 2012.

HARVEY, David. Condição Pós-Moderna. São Paulo: Loyola, 2012.

LEFEBVRE, Henri. 0 direito à cidade. São Paulo: Centauro, 2001.

MASCARENHAS, Fernando. Copa pra quem? In: Blog de Fernando Mascarenhas. Disponível em: < http://blogdomasca.blogspot.com.br/2013/01/copa-pra-quem.html >. Acesso em: 15 ago. 2013.

MASCARENHAS, Fernando. Megaeventos esportivos e Educação Física: alerta de tsunami. Movimento, Porto Alegre, v. 18, n. 1, p. 39- 67, jan/mar., 2012a.

MASCARENHAS, Gilmar. Desenvolvimento urbano e grandes eventos esportivos: o legado olímpico nas cidades. In: MASCARENHAS, Gilmar.; BIENENSTEIN, Glauco; SÁNCHEZ, Fernanda. (Org.). 0 jogo continua: Megaeventos Esportivos e Cidades. Rio de Janeiro: EdUERJ, 2011. p. $27-39$.

MINISTÉRIO DO ESPORTE. Copa 2014. Disponível em:<http://www.esporte.gov.br/index.php/ institucional/futebol-e-direitos-do-torcedor/copa-2014/cidades-sede >. Acesso em: 20 ago. 2014.

RAEDER, Savio. Conflitos no ordenamento territorial em grandes eventos esportivos. In: MASCARENHAS, Gilmar; BIENENSTEIN, Glauco; SÁNCHEZ, Fernanda. (Org.). 0 jogo continua: Megaeventos Esportivos e Cidades. Rio de Janeiro: EdUERJ, 2011.

RODRIGUES, Rejane Penna; PINTO, Leila Mirtes Magalhães. Subsídios para pensar os legados de megaeventos esportivos em seus tempos presente, passado e futuro. In: DACOSTA, Lamartine et al. (Org.). Legados de Megaeventos Esportivos. Brasília: Ministério do Esporte, 2008. p. 21-25.

ROLNIK, Raquel. 0 que é cidade? São Paulo: Brasiliense, 2012.

SANTOS, Milton. 0 mundo global visto do lado de cá. Documentário. Produção de Silvio Tendler. Caliban Produções Cinematográficas, 2006. (90 min.): DVD, Ntsc, son., color.

STEINHILBER, Jorge. O Brasil está envolto em um verdadeiro tsunami esportivo. Revista da Educação Física (CONFEF), Rio de Janeiro, n. 40, p. 1, 2011.

STEINHILBER, Jorge. O profissional de Educação Física e os legados de Megaeventos Esportivos. In: DACOSTA, Lamartine et al.(Org.). Legados de Megaeventos Esportivos. Brasília: Ministério do Esporte, 2008. p.75- 76.

TAVARES, Otavio. Megaeventos Esportivos. Movimento, Porto Alegre, v. 17, n. 3, p. 11-35, jul/set. 2011.

VAINER, Carlos Bernardo. Prefácio. In: MASCARENHAS, Gilmar; BIENENSTEIN, Glauco; SÁNCHEZ, Fernanda. (Org.). 0 jogo continua: Megaeventos Esportivos e Cidades. Rio de Janeiro: EdUERJ, 2011. p. 9-15.

VILLANO, Bernardo et al. Seminário "Gestão de Legados de Megaevento Esportivos": Pontos de Convergência. In: DACOSTA, Lamartine et al (Org.). Legados de Megaeventos Esportivos. Brasília: Ministério do Esporte, 2008. p. 47-50. 